\title{
Teologia em kênosis como caminho da paz
}

\author{
Theology in kenosis as way of peace
}

Marcio Simão de Vasconcellos

\section{Resumo}

A revelação de Deus ocorre por meio de uma mediação histórico-cultural através da qual o ser humano experimenta o encontro com o Deus-Mistério. Portanto, toda teologia vincula-se intimamente a uma antropologia. No caso da fé cristã, isso é ainda mais verdadeiro pois, segundo o Novo Testamento, a plenitude da revelação de Deus vem até nós através de Jesus, o próprio Deus que se fez carne, o Deus-Emanuel. Portanto, cristologia e antropologia se relacionam mutuamente na vivência e encarnação da fé cristã assim como na prática teológica que dela surge. $\mathrm{O}$ critério cristológico, lido na perspectiva bíblica da kênosis trinitária, revela-se, ainda, central à compreensão da missão da comunidade de fé em anunciar e promover a paz. Afirmamos essa kênosis divina como modelo para a compreensão do humano e para a implantação e manutenção da paz no mundo por meio da reflexão e da prática teológica e da vivência da igreja. A partir do exemplo do próprio Cristo, buscamos (re) pensar a teologia cristã a fim de que ela também se torne serva, inclusiva em sua abordagem, amiga de pecadores, promotora da igualdade de gênero, defensora dos pobres e excluídos, buscadora de Deus, profética e anunciadora da paz.

Palavras-chave: Kênosis. Cristologia. Antropologia. Teologia.

\section{Abstract}

The revelation of God occurs through a historical-cultural mediation 
through which the human being experiences the encounter with the GodMystery. Therefore, all theology is linked intimately to an anthropology. In the case of the Christian faith, this is even more true because, according to the New Testament, the fullness of God's revelation comes to us through Jesus, God Himself who became flesh, the God-Emanuel. Therefore Christology and anthropology relate to each other in living and incarnation of the Christian faith as well as in the practical theology that arises out of it. The Christological criterion, read in the biblical perspective of the Trinitarian kenosis, reveals itself, also central to understanding the mission of the faith community to announce and promote peace. We affirm the divine kenosis as a model for the understanding of human and deployment and peacekeeping in the world through reflection and theological practice and experience of the church. From the example of Christ himself, we seek to think Christian theology so that it also becomes servant, inclusive in his approach, a friend of sinners, promoting gender equality, defender of the poor and excluded, God-seeking, prophetic and herald of peace.

Keywords: Kenosis. Christology. Anthropology. Theology.

\section{Introdução}

Desejamos iniciar nossa reflexão a partir de um trecho do discurso do Papa Francisco, quando em visita ao Brasil por ocasião da Jornada Mundial da Juventude, em julho de 2013. Diz o Papa:

Precisamos de uma Igreja que saiba dialogar com aqueles discípulos, que, fugindo de Jerusalém, vagam sem meta, sozinhos, com o seu próprio desencanto, com a desilusão de um cristianismo considerado hoje um terreno estéril, infecundo, incapaz de gerar sentido. ${ }^{1}$

Essas palavras do Papa Francisco ressaltam a necessidade da igreja e da própria teologia repensarem, à luz do evangelho, sua própria identidade. Num tempo como o nosso, de tantas propostas de espiritualidade ditas cristãs e de uma mudança de paradigma que alcança e transforma todas as dimensões da vida, é preciso parar e olhar para dentro de si, tarefa nunca fácil de ser

${ }^{1}$ PAPA FRANCISCO. Palavras do Papa Francisco no Brasil. São Paulo: Paulinas, 2013, p. 96. 
realizada. Nesse processo, é preciso unir duas qualidades que, como afirma Alfonso Garcia Rúbio, estiveram desde cedo presentes na prática teológica cristã: coragem e discernimento. Como afirma o teólogo:

\begin{abstract}
Nessa abertura crítica ao mundo cultural greco-romano, prevaleceu, em termos gerais, o dinamismo que articula a coragem (para se abrir e acolher o mundo cultural dos outros) e o discernimento (para saber distinguir o que pode ser assimilado da outra cultura e o que deve ser rejeitado, em nome da identidade profunda da fé cristã). ${ }^{2}$
\end{abstract}

Toda teologia se expressa por meio de uma mediação cultural. Já se disse, e com razão, que toda teologia traz consigo uma antropologia e viceversa. $\mathrm{Na}$ verdade, a teologia fala não somente de Deus mas também do humano. Tal afirmativa é a base sobre a qual é possível pensar a formação da identidade humana - e da teologia e da igreja - a partir da identidade do Deus que se revela a nós. Se falar de Deus implica em falar do humano - afirmação que, embora ousada para muitos, revela-se como fundamento da própria atividade teológica - então nossa antropologia e nossa teologia (e tudo relacionado a ela) refletirão as características da imagem de Deus que desenvolvemos em nossa vida de fé. Dito de outra maneira: a nossa forma de ver a Deus implicará numa forma específica de ver o ser humano, de definir a igreja e de fazer teologia. Ou, como afirma enfaticamente Gesché: "a ideia que fazemos do homem revela com toda certeza a ideia que fazemos de Deus (e, sem dúvida nenhuma, a recíproca também é verdadeira)"3.

Dessa forma, à nossa compreensão sobre a identidade divina, corresponde uma identidade do ser humano, uma percepção da própria vida que irá determinar nossa prática teológica. Dito de outra maneira: a maneira com que enxergamos a Deus será a lente usada na elaboração de nossa teologia, aplicada à compreensão da igreja e das nossas relações com os outros. Assim, uma imagem torta de Deus (opressivo, acusador, eternamente irado) trará à luz uma teologia igualmente adoecida.

\footnotetext{
${ }^{2}$ RUBIO, Alfonso Garcia. "A teologia da criação desafiada pela visão evolucionista da vida e do cosmo". In: AMADO, Joel Portella; RUBIO, Alfonso Garcia (Orgs.). Fé cristã e pensamento evolucionista. São Paulo: Paulinas, 2012, p. 18.

${ }^{3}$ GESCHÉ, Adolphe. Deus. Coleção Deus para pensar. Volume 3. São Paulo: Paulinas, 2004, p. 103.
} 


\section{A encarnação como critério teológico: o rosto do Pai revelado no Filho}

À luz dessa realidade, torna-se primordial refletirmos cuidadosamente sobre e a partir de qual imagem de Deus estamos elaborando nossas teologias. E o critério para fazer isso é o da encarnação de Jesus, o Cristo de Deus. Como bem esclarece o Documento de Aparecida:

Deus é a realidade fundante, não um Deus só pensado ou hipotético, mas o Deus de rosto humano; é o Deus-conosco, o Deus do amor até a cruz. Quando o discípulo chega a compreensão deste amor de Cristo "até o extremo", não pode deixar de responder a este amor se não é com um amor semelhante: "Eu te seguirei por onde quer que fores" ( $\operatorname{Lc} 9,57){ }^{4}$

Toda a fé cristã está baseada num evento central da teologia: a encarnação. Mas o que significa isso? Certamente, precisamos afirmar que a encarnação não significa um Deus "caindo" feito um meteoro na terra, em qualquer lugar. Também não significa que Jesus foi um mero visitante em meio à humanidade, como se Ele não tivesse assumido a encarnação até as últimas consequências. Não! A encarnação e tudo relacionado a ela (inclusive o chão por onde Jesus andou) foi proposital.

A fonte da fé cristã é Jesus tal qual este é apresentado nas páginas do Novo Testamento. Referimo-nos, portanto, a esse Jesus, que foi a casamentos não para fazer milagres, mas para aproveitar a vida diante de Deus juntamente com o próximo; esse Jesus que chorou com a incompreensão daqueles e daquelas que não se abriam para a chegada do reino de Deus; esse Jesus que exultou em espírito ao perceber que os segredos do reino de Deus eram revelados aos pobres; esse Jesus que caminhou e comeu com gente que, na perspectiva dos religiosos dos seus dias, não valiam nada. É o Deus encarnado, que viveu integralmente sua própria história na história dos homens e mulheres do século I da era cristã ${ }^{\text {. }}$

\footnotetext{
${ }^{4}$ DOCUMENTO DE APARECIDA. Texto conclusivo da V Conferência Geral do Episcopado Latino-Americano e do Caribe. São Paulo / Brasília: Paulus / Paulinas / CNBB, 2014, p. 255.

${ }^{5}$ Aliás, nesse sentido, precisamos rejeitar uma visão despolitizada de Jesus e de seu ambiente. Reduzir Jesus a uma figura meramente religiosa, dissociando sua pregação e vida dos aspectos políticos, sociais, religiosos e econômicos de seu tempo, gera um Jesus "domesticado" que pode ser (e tem sido durante toda a história do cristianismo) apropriado por diferentes visões de mundo, algumas bastante contrárias ao Reino de Deus.
} 
Pois bem, a vocação da igreja e da teologia é fazer deste Deus revelado em Jesus - deste Deus que se faz presente conosco todos os dias - o molde para sua atuação no mundo. Deus se fez humano em Jesus. A encarnação revela-se, portanto, como um dos mais importantes (senão o mais importante) assunto da teologia. "Deus vem a nós primordialmente na história de Jesus e seus feitos." de Deus. Como afirma Maria Clara Bingemer,

Em Jesus Deus mesmo e não outro é quem se aproxima do ser humano. A humanidade de Jesus é lugar de encontro de Deus com o ser humano. Trata-se de um Deus humano, um Deus feito carne, encarnado, que vem a nosso encontro, que não pretende isolar-se em uma morada inacessível, desde a qual atuaria através de intermediários. ${ }^{7}$

Jesus não usurpou o ser igual a Deus, mas antes esvaziou-se a si mesmo assumindo figura humana (cf. Fp 2.5-8). Dessa forma, é o próprio Deus que está presente em Jesus, cuja companhia e amizade foram desfrutadas pelos(as) discípulos(as).$^{8} \mathrm{O}$ caminho, a verdade e a vida (cf. Jo 14.6) são, nesse sentido e antes de tudo, uma Pessoa: Jesus de Nazaré, o próprio Deus encarnado. A teologia torna-se enfraquecida quando resume essas categorias à fórmulas racionalistas ou doutrinas pré-estabelecidas. É preciso lembrar que de Deus "só se pode balbuciar e falar de uma maneira muito indireta" . Por isso, falando da encarnação como o centro da fé, Karl Rahner pode afirmar:

Para que em cada caso o cristianismo se faça realidade no sentido pleno, necessário e autêntico da palavra devem ocorrer ainda muitas coisas: o encontro deste acontecimento primordial cristão com sua própria aparição histórica em Jesus Cristo, em quem este Deus inefável "está realmente presente" para nós na história, na palavra, no sacramento e na comunidade que confessa, que chamamos de Igreja. Mas este cristianismo expresso,

\footnotetext{
${ }^{6}$ BOSCH, David J. Missão transformadora: mudanças de paradigma na teologia da missão. São Leopoldo: Sinodal, p. 41.

${ }^{7}$ BINGEMER, Maria Clara L. Jesus Cristo: servo de Deus e Messias glorioso. São Paulo: Paulinas, 2008, p. 143.

${ }^{8}$ Cf. RUBIO, Alfonso Garcia. O encontro com Jesus Cristo vivo: um ensaio de cristologia para nossos dias. São Paulo: Paulinas, 2003, p. 162.

${ }^{9}$ RAHNER, Karl. La gracia como libertad. $3^{\text {a }}$ ed. Barcelona: Herder, 2008, p. 26.
} 
refletido e institucional, necessário e santo, só alcança seu sentido, só deixa de ser a mais sublimada das idolatrias, quando realmente indica e inicia aos homens na entrega confiada e amorosa ao mistério santo e sem nome; entrega que realiza a liberdade, assim que se deixa dar por esse mesmo mistério silencioso e, desse modo, nossa resposta procede da "palavra de Deus". ${ }^{10}$

Este esvaziamento da divindade, essa kênosis, revelou a face divina aos seres humanos. Face que só pode ser compreendida porque ela mesma se abre e se revela às claras. Mas também face que permanece misteriosa, segredo relacional preservado no quarto fechado, quando se ora ao Pai sem olhares outros senão o do próprio Amor que nos convida à comunhão mística (cf. Mt 6.6). Daí a linguagem para Deus ser forçosamente metafórica e simbólica, ambígua até. Deus Pai, como bela e poeticamente expressa Rahner, é "seriedade que ama alegremente, o começo que é nosso futuro, o soberano santo que leva a cabo sua obra com grande paciência, sem pressa, sem medo de nossas queixas desesperadas nem de nossas acusações impacientes." ${ }^{11}$.

As curas, as ações, as escolhas e os discursos de Jesus sobre si mesmo e sobre sua relação com o Pai atestavam, aos olhos das elites religiosas judaicas, o escândalo desta imagem de Deus que o Nazareno anunciava. "Por isso", diz João, "os judeus ainda mais procuravam matá-lo porque não somente violava o sábado, mas também dizia que Deus era seu próprio Pai, fazendo-se igual a Deus." (Jo 5.18). Ao que parece, o Deus revelado em e por Jesus não era o mesmo cultuado diuturnamente nas liturgias do Templo em Jerusalém. E o próprio Jesus confirma esse diagnóstico ao dirigir-se aos fariseus e exclamar em alto e bom som: "Não me conheceis a mim nem a meu Pai." (Jo 8.19), "vós sois do diabo, que é vosso pai, e quereis satisfazer-lhe os desejos. (...) Não me dais ouvidos porque não sois de Deus." (Jo 8.44,47).

Isso, porém, era o que as autoridades religiosas de então não podiam tolerar. Deus não era como a imaginação deles o concebia. E, seguramente, como lhes convinha. Deus era tão desconcertante quanto desconcertante era aquele Jesus que eles tinham diante de si. (...) Se era verdade o que Jesus dizia, não tinham outra saída a não ser aceitar que Deus age no mundo do mesmo modo que Jesus agia: relativizando o absoluto da submissão

\footnotetext{
${ }^{10}$ Ibid., p. 29.

${ }^{11}$ Ibid., p. 33.
} 
à Lei e absolutizando a luta contra o sofrimento humano. Isso, porém, desmontava "seu deus" e lançava por terra "seus poderes. ${ }^{12}$

Dessa maneira, a encarnação revela o modo de ser do próprio Deus. A relação entre o Pai e Jesus é tão íntima e perfeita que todos os que enxergam a Jesus também encontram, Nele, o Pai revelado (cf. Jo 14.9-10), o Pai de amor da parábola do filho pródigo (Lc 15.20-24), o Pai santo e justo da oração sacerdotal (cf. Jo 17.11,25), o Pai que não faz acepção de pessoas, pois faz nascer o seu sol sobre bons e maus e vir sua chuva sobre justos e injustos (cf. Mt 5.45). É por meio dessa revelação encarnada, aliás, que conhecemos os lugares de Deus, isto é, os locais de sua manifestação que fornecem sentido e conteúdo à vida humana.

Conhecemos os lugares de Deus perguntando-nos pelos lugares do Deus de Jesus Cristo, lugar revelador de Deus, lugar por excelência da busca e do encontro com Deus, a partir de sua decisão de Encarnação. Buscar os espaços de transcendência a partir da experiência cristã de Deus significa procurar a Deus ali onde ele se doa e da maneira como ele quer ser conhecido. ${ }^{13}$

Esses lugares de transcendência, diga-se de passagem, nem sempre são os mesmos estabelecidos pela religião como templos sagrados e espaços de culto. Em pouquíssimas ocasiões, Jesus foi encontrado no Templo em Jerusalém. E mesmo nesses momentos, sua presença ali trazia denúncia e juízo ${ }^{14}$.

$\mathrm{Na}$ encarnação, o Deus feito homem se alegra com a vida que Ele mesmo fez, pois tudo era "muito bom" (cf. Gn 1.31). O Deus encarnado enxerga as flores do campo e as aves do céu como espaço litúrgico para falar da Sua

\footnotetext{
${ }^{12}$ CASTILlO, José Maria. Deus e nossa felicidade. São Paulo: Loyola, 2006, pp. 59-60.

${ }^{13}$ PEDROSA-PÁDUA, Lúcia. "Espaços de Deus: pistas teológicas para a busca e o encontro de Deus na sociedade plural”. In: OLIVEIRA, Pedro A. Ribeiro de; MORI, Geraldo de (Orgs.). Deus na sociedade plural: fé, símbolos, narrativas. São Paulo: Paulinas, 2013, p. 24.

14 "O gesto de Jesus", afirma José Antonio Pagola, "é mais radical e total. Anuncia o juízo de Deus não contra aquele edifício, mas contra um sistema econômico, político e religioso que não pode agradar a Deus. O templo se transformou em símbolo de tudo quanto oprime o povo. Na 'Casa de Deus' acumula-se a riqueza; nas aldeias de seus filhos cresce a pobreza e o endividamento. O templo não está a serviço da Aliança”. (PAGOLA, José Antonio. Jesus: aproximação histórica. $3^{\mathrm{a}}$ ed. Petrópolis: Vozes, 2011, p. 431). Não se trata, portanto, de mera purificação do Templo, mas antes de sua destruição para que a relação com Deus verdadeira e sadia pudesse brotar.
} 
providência para com sua criação (cf. Mt 6.26-30); convida à sua mesa gente de reputação duvidosa, fornecendo-lhes a graça do arrependimento (Lc 5.29-32). Também visita casas de chefes da sinagoga, onde reina a morte e a putrefação, e lá fornece a força e a vida da Sua ressurreição: "Menina, levantate!" (Lc 8.54). O Deus encarnado também participa de casamentos, regado a bom vinho fornecido até a última hora, festejando com amigos o fato de que o homem deixa sua mãe e seu pai e se une a mulher tornando-se uma só carne (cf. Gn 2.23-24; Jo 2.1-11). Também chora pela morte de um amigo querido mas não se rende ao desespero da dor; antes, ressalta a esperança da ressurreição (cf. Jo 11).

Esta imagem que os evangelhos apresentam do Deus-Emanuel é o critério para julgarmos nossas teologias e eclesiologias. "Assim como o Pai me enviou", diz Jesus a seus discípulos, "eu também vos envio" (Jo 20.21). Portanto, a maneira de ser igreja e de pensar teologicamente deve ser pautada pela vida, morte e ressurreição de Jesus. Se é assim, que consequências possui tal imagem kenótica para a compreensão da nossa prática teológica?

\section{Consequências da encarnação (kênosis) para a prática teológica}

A kênosis divina propõe uma pauta ética para a teologia e a igreja. Antes de tudo, seguindo o exemplo do próprio Cristo, uma teologia em kênosis revela-se a caminho. Quando os discípulos no evangelho de João perguntam a Jesus “Onde moras?" (isto é, querem conhecer quem é esse Jesus), a resposta não é uma frase pronta, nem um roteiro de viagem pré-programado; a resposta é um convite: "Vem e vê." (cf. Jo 1.38-39). Isto significa que o seguimento de Jesus, o discipulado, não é uma estrada fixa no horizonte, mas, como diz o poeta Antônio Machado, é um caminho que se faz ao andar. É o jeito como se caminha na vida que forma a estrada. Isso implica num dinamismo e numa abertura ao sopro do Espírito Santo que sopra onde quer, e sabe, melhor que nós, o que manter e o que retirar de nossas teologias sistemáticas.

Uma teologia em kênosis também revela-se aberta ao outro. Mostra-se pronta a dialogar, sobretudo com o diferente. Ecumenismo e diálogo inter-religioso fazem parte de sua pauta de reflexão e ação porque se compreende que o encontro com o outro faz parte do processo de maturação da própria identidade. A intolerância, por outro lado, característica de imagens tortas de Deus, certamente se manifestará em práticas pastorais, teológicas e eclesiásticas igualmente intolerantes. Homens e Deus tornam-se, nessa lógica, respectivamente semi 
-homens e falsos deuses, pois não há nada mais destrutivo do que aquele que se propõe a falar "em nome de Deus" mas faz isso a partir do seu próprio coração inchado de orgulho, medo, ódio e fanatismos, e nada mais assustador do que ter que encarar os olhares fixos e sempre perscrutadores desses deuses idolátricos. Não há espaço para a paz enquanto seres humanos desumanizam-se mutuamente em nome de uma imagem idolátrica de Deus. Uma teologia em kênosis, ao contrário, saberá ser sem destruir identidades alheias, pois se reconhece vazia de si mesmo para o serviço ao mundo e a Deus.

A encarnação e a kênosis de Jesus apontam um caminho para a teologia e para a igreja. De fato, toda cristologia conduz a uma eclesiologia. É a mensagem, vida, morte e ressurreição de Jesus que fornecem o critério para quaisquer reflexões sobre a identidade da igreja. Como aponta a Lumen Gentium, "o mistério da santa Igreja manifesta-se logo na sua fundação. O Senhor Jesus deu início à sua Igreja com a pregação da Boa-Nova, quer dizer, da vinda do reino de Deus". ${ }^{15}$

Uma primeira e importante consequência de tal afirmação é compreender a igreja como sinal realizador do reino de Deus. Nesta condição, a igreja não é receptáculo aprisionador do Espírito de Deus (que sempre sopra onde quer), nem a detentora da salvação ou do agir divino sobre o mundo. Antes, ela é sinal que aponta para algo maior do que ela mesma. Essa coisa que o sinal aponta - isto é, a realidade do reino de Deus - "não deve ser confundida com a precariedade de seu sinal. Apenas pela diferenciação entre o sinal e coisa essa última pode estar de certo modo presente através de seu sinal"16. Nesse sentido, continua Pannenberg:

Essa é também a situação de igreja e reino de Deus. A igreja tem de diferenciar a si mesma da futura comunhão dos humanos no reino de Deus, para ser reconhecível como sinal do reino de Deus, por meio do qual seu futuro de salvação já se torna atual para as pessoas em sua respectiva época. Quando a igreja deixa de tornar explícita essa diferença, ela arroga a si mesma o caráter definitivo e a glória do reino de Deus, privando em contrapartida de credibilidade a esperança cristã por causa da miserabilidade e o caráter demasiadamente humano de sua própria vivência. ${ }^{17}$

\footnotetext{
${ }^{15} \mathrm{LG} \mathrm{n}^{\circ} 5$.

${ }^{16}$ PANNENBERG, Wolfhart. Teologia sistemática. Volume III. São Paulo: Paulus, 2009, p. 64.

${ }^{17}$ Ibidem.
} 
Por ser sinal realizador do reino, a igreja concretiza a mensagem deste reino em prática atuante sobre a vida cotidiana. O reino de Deus - justiça, paz e alegria do Espírito Santo (cf. Rm 14.17) - se torna realidade presente na vivência eclesiástica. Assim, a igreja anuncia a justiça, mas também tornase, ela mesma, agente de justiça no mundo; ela prega a paz, mas também a promove, interna e externamente, de forma constante; ela proclama a alegria que sustenta a vida, mas ela mesma revela-se como fonte de alegria que dinamiza a vida e que não aprisiona as pessoas. Enfim, se o caminho da igreja é o mesmo proposto por Jesus, então ela também deve assumir-se como inclusiva, amiga de pecadores, promotora da igualdade de gênero, defensora dos pobres e excluídos, buscadora de Deus e profética em sua palavra, plenamente identificada com seu próprio tempo. O que Jesus foi em seu tempo, a igreja é chamada a ser, até mesmo superando seu Mestre na prática dessas boas obras (cf. Jo 14.11-12).

A igreja não é triunfante por si mesma, mas em Cristo. Ora, se é assim, então o triunfo de Jesus é o modelo para a Igreja, a saber: o triunfo da cruz que não nega o sofrimento de viver nem a alegria de morrer, mas que conjuga a encarnação, a vida, a morte e a ressurreição de Jesus em sua própria prática pastoral e teológica. Do ponto de vista pastoral, reconhecer isso implica em partilhar e participar das alegrias e dores desse mundo, ajudando a todos e a todas a carregarem sua cruz. Implica em descer de pedestais gerados por orgulho e insensibilidade e ajoelhar-se diante das pessoas a fim de lavar-lhes os pés.

Do ponto de vista teológico, reconhecer isso implica em evitar reducionismos que ou enfatizam o aspecto escatológico da igreja, ou rejeitam a esperança do porvir. Somos os mais miseráveis de todos os homens se nossa esperança em Cristo se limita apenas a esta vida (cf. $1^{\text {a }}$ Co 15.19), mas somos igualmente infelizes se não reconhecemos nossa responsabilidade em estabelecer o reino de Deus sobre a terra mediante o poder do Espírito de Jesus. Encarnação, cruz e ressurreição constituem, assim, o caminho da igreja, seu rosto e sua identidade.

A um Cristo que se esvazia de si mesmo para, de forma humilde, servir aos outros, corresponde uma igreja e uma teologia que, de igual modo, toma a toalha e a bacia com água nas mãos para lavar os pés dos homens e mulheres de nosso tempo, sobretudo dos mais empobrecidos. Essa imagem não é apenas inspiradora; na verdade, constitui o cerne mesmo da missão cristã e da formação da igreja. Esta, reconhecendo o senhorio e o messianismo de 
Jesus (cf. Jo 13.13), é chamada por Ele a ir e fazer o mesmo aos outros (cf. Jo 13.14-17).

Nesse sentido, não há meias palavras ou posicionamentos parciais: o serviço aos outros exigirá da igreja e da teologia uma abertura, um reconhecimento de sua própria fragilidade, uma assunção dos riscos do amor que pode ser rejeitado e que faz sofrer, uma postura de escuta atenta (e não de discursos inflamados em defesa de sua própria doutrina), um olhar menos intolerante e mais dialogal, enfim um caminho mais semelhante ao do próprio Filho de Deus que não veio para ser servido, mas para servir (cf. Mt 20.28).

Com sinal escatológico, a igreja necessariamente será um sinal de contradição e, salvo completo engano, o conflito entre o Reino de Deus e o reino deste mundo entra atualmente numa nova fase dramática. Não deveríamos alimentar ilusões a respeito. Os poderes da impiedade e do mal investem contra a igreja também em nosso tempo e em parte estão ativos até dentro da igreja. A igreja do futuro não tem alternativa senão postar-se sob o sinal da cruz. ${ }^{18}$

Os lugares da igreja e também os da teologia devem ser os mesmos percorridos por Jesus: as periferias do mundo; as margens das praias, junto a pescadores e pecadores; a mesa da partilha, convite aberto para a entrada no Reino do Pai. Os olhares da igreja e da teologia devem ser os mesmos praticados por Jesus: enxergar pessoas como indivíduos, valorizando-os como filhos e filhas de Deus e não como massa de manobra ou base sustentadora de uma hierarquia espúria e injusta; enxergar o sofrimento de mães, viúvas, que perdem seus filhos nas favelas (cf. Lc 7.11-17), de pais que são impotentes para ajudar seus filhos doentes (cf. Mc 9.14-27), de cegos de nascença que nunca foram vistos pelos religiosos fariseus mas que são percebidos pelo Senhor (cf. Jo 9). Enfim, os projetos da igreja devem ser os mesmos projetos de Jesus: não busca pelo poder, mas caminhos de serviço a Deus e ao próximo; não projeção pessoal mas o anonimato do sal e do fermento que se misturam aos alimentos e não são mais percebidos visualmente, embora seus efeitos sejam percebidos como sabor agradável e salutar.

Por fim, a encarnação de Deus implica em cremos na esperança e em agirmos em função dela. Nesse sentido, não há lugar para imobilidade passiva

\footnotetext{
${ }^{18}$ KASPER, Walter. A Igreja Católica: essência, realidade, missão. Coleção Theologia Publica, 8. São Leopoldo: Unisinos, 2012, p. 418.
} 
diante das dores do mundo. Antes, somos vocacionados a experimentar junto com as pessoas as "alegrias e as esperanças, as tristezas e as angústias"19 de tudo o que constitui a natureza humana. Ao fazermos essa boa experiência, enriqueceremos nossa prática teológica com a profundidade da encarnação que lhe fornece poder para transformar o mundo. Esse é o encanto do evangelho, como bem expressa o teólogo luterano Milton Schwantes:

\begin{abstract}
"Você já viu a violetinha em flor lá no cantinho da cozinha?" Eis o boato que corre. E cada qual vai lá apreciar seu encanto. "E, olha, lá meio escondido, mais dois botõezinhos!". "Ah, que lindo" E lá vamos à cozinha, ver as florzinhas. Até parece peregrinação. E quem vem de visita é, sem seguida, conduzido à florzinha, no cantinho da cozinha. Deu-me a ideia de que aí temos um Evangelho. Vem do cantinho. Lá no meio de um escuro lugar se nos anuncia uma boa-nova: há flor até onde a luz é pouca. ${ }^{20}$
\end{abstract}

Essa luz que vem ao mundo e que vence as trevas (cf. Jo 1.5) deve se fazer presente no refletir teológico da igreja. A teologia se constrói na lógica desafiadora do seguimento de Jesus. Tal proposta significa anunciar a esperança do reino de Deus. O evangelho é boa-notícia e só é boa-notícia porque está repleto de esperança. Uma teologia em kênosis, em que pese as aflições da vida, fará da esperança sua base e seu pão cotidiano.

\title{
Conclusão
}

Reafirmemos: o modelo de missão da igreja e da prática teológica precisam ser cristológicos, isto é, pautado por uma vida simples, encarnacional, compassiva e solidária aos seres humanos, sobretudo aos mais empobrecidos e excluídos. Evangelizar é falar uma boa notícia. Mais que falar, é viver essa novidade boa, alegre, pacificadora, coerente e reestruturadora da vida. Sendo assim, não se evangeliza com opressão, legalismos, literalismos ou fundamentalismos, todos cooperadores na formação de uma visão de vida monótona, agressiva e triste e na deformação da imagem humana e divina. Deus nos criou à sua imagem e semelhança (cf. Gn 1.26-17). Não rejeitemos essa vocação de sermos, na existência concreta e como comunidade de fé, semelhantes ao Pai. É aí que reside a força da Igreja e da teologia que trazemos à luz.

\footnotetext{
${ }^{19}$ Cf. Gaudium es spes, n. 1.

${ }^{20}$ SCHWANTES, Milton (et al). 365 dias com Deus. São Paulo: Cedro, 2010.
} 


\section{Referências bibliográficas}

BINGEMER, Maria Clara L. Jesus Cristo: servo de Deus e messias glorioso. São Paulo: Paulinas, 2008.

BOSCH, David J. Missão transformadora: mudanças de paradigma na teologia da missão. São Leopoldo: Sinodal, 2002.

CASTILlO, José Maria. Deus e nossa felicidade. São Paulo: Loyola, 2006.

CONSTITUIÇÃO DOGMÁTICA DO CONCÍLIO ECUMÊNICO VATICANO II SOBRE A IGREJA. Lumem Gentium "De Ecclesia". 23" edição. São Paulo: Paulinas, 2011.

CONSTITUIÇÃO PASTORAL. Gaudium et spes. $3^{\mathrm{a}}$ edição. Petrópolis: Vozes, 1980.

DOCUMENTO DE APARECIDA. Texto conclusivo da V Conferência Geral do Episcopado Latino-Americano e do Caribe. São Paulo / Brasília: Paulus; Paulinas; CNBB, 2014.

GESCHÉ, Adolphe. Deus. Coleção Deus para pensar. Volume 3. São Paulo: Paulinas, 2004.

KASPER, Walter. A Igreja católica: essência, realidade, missão. Coleção Theologia Publica, 8. São Leopoldo: Unisinos, 2012.

PAGOLA, José Antonio. Jesus: aproximação histórica. $3^{\mathrm{a}}$ ed. Petrópolis: Vozes, 2011.

PANNENBERG, Wolfhart. Teologia sistemática. Volume III. São Paulo: Paulus, 2009.

PAPA FRANCISCO. Palavras do Papa Francisco no Brasil. São Paulo: Paulinas, 2013.

PEDROSA-PÁDUA, Lúcia. "Espaços de Deus: pistas teológicas para a busca e o encontro de Deus na sociedade plural". In: OLIVEIRA, Pedro A. Ribeiro de; MORI, Geraldo de (Orgs.). Deus na sociedade plural: fé, símbolos, narrativas. São Paulo: Paulinas, 2013.

RAHNER, Karl. La gracia como libertad. $3^{\text {a }}$ ed. Barcelona: Herder, 2008.

RUBIO, Alfonso Garcia. "A teologia da criação desafiada pela visão evolucionista da vida e do cosmo". In: AMADO, Joel Portella; RUBIO, 
Alfonso Garcia (Orgs.). Fé cristã e pensamento evolucionista. São Paulo: Paulinas, 2012.

RUBIO, Alfonso Garcia. O encontro com Jesus Cristo vivo: um ensaio de cristologia para nossos dias. $8^{\text {a }}$ ed. São Paulo: Paulinas, 2003.

SCHWANTES, Milton (et al). 365 dias com Deus. São Paulo: Cedro, 2010.

Marcio Simão de Vasconcellos

Doutorando em teologia sistemático-pastoral (PUC-Rio)

Mestre em teologia sistemático-pastoral (PUC-Rio)

Especialista em Ciências da Religião (FATERJ)

Bacharel em teologia pela Universidade Metodista de São Paulo (UMESP)

Rio de Janeiro / RJ - Brasil

E-mail: marciosvasc@gmail.com

Recebido em: 21/09/15

Aprovado em: 05/04/16

846 ATeo, Rio de Janeiro, v. 20, n. 54, p. 833-846, set./dez.2016 